\title{
Design of PV-Wind Turbine Mobile Container for Disaster Area Using Homer: A Case study in Cepu - Central Java
}

\author{
A Sahrin ${ }^{1, *}$ E Utami ${ }^{1}$ M. A Fathoni ${ }^{1}$ \\ ${ }^{1}$ Politeknik Energi dan Mineral Akamigas Cepu, Indonesia \\ "Corresponding author.Email: alfin.sahrin@esdm.go.id
}

\begin{abstract}
This paper purpose to design a system in the form of a PV (module) - Wind Turbine Mobile container for the first solution of the disaster area application in the Cepu city of Blora, Central Java. The solution given is to make a mobile container that can assemble a short time as an independent renewable energy source with the devices used to help supply energy and easy to move. The design use hybrid energy consist of PV (module), wind turbine, inverter, water pump, reverse osmosis, lighting, and charger facilities for communication equipment. In the design process using the HOMER software, it can design a system and simulate and determine the best system configuration. In this paper, model four configurations between the power capacity of the PV (module) and the wind turbine to obtain the optimal configuration. The simulation result show configuration of 1 proposed grid-connected with load profile load is 9267-watt using capacity PV (module) $250 \mathrm{wP}$ and a wind turbine $1 \mathrm{~kW}$, and this system is feasible to apply.
\end{abstract}

\section{Keywords: Mobile Container, Disaster Area, Hybrid Energy, Homer Software.}

\section{INTRODUCTION}

In the event of a natural disaster, electric power is usually the first essential service that is lost. Housing, hospitals, schools, food stores, and other vital services are in dire need of electricity for various needs [1]. Renewable energy is suitable in this situation. Photovoltaic (PV) power systems and wind turbines are examples of environmentally friendly technologies that provide free electricity that is reliable, safe, noise-free, and does not require refueling. It also helps to reduce the consumption of fossil fuels in power generation, pollution, and greenhouse gas emissions that cause climate change [2].

The alternative in the first countermeasures to disaster is to install a hybrid PV-Wind system on the container, moving the energy supply wherever it is needed and moving it back as needed. The PV-Wind Mobile power system is a standalone system that can use to provide electricity to communication stations, hospital, ensconce, and homes at disaster sites before electric utilities available [3]. The combination of the PV-Wind power system is very suitable to be applied in the Cepu area because the potential for solar and wind is sufficient and other parts of Indonesia. After all, it is in the tropics
[4]. The system can be assembled in short time and can replace fossil generators for temporary power in many applications.

Based on this, this study will make a portable clean energy design for the needs of the first countermeasures in the event of a natural disaster with loads including; water pumps that can be used to serve the water needs of people affected by disasters, reverse osmoses as a means of providing drinking water needs, lighting and charger facilities for communication needs when a natural disaster occurs. The planning stage is the stage to determine the capacity of the energy produced with the necessary load requirements. The weather factor also determines the combination of $\mathrm{PV}$ and wind turbines because the design in each area will be different [5]-[7]. After all, it will have an impact on the selection of components and costs. Designing hoped balanced energy be obtained between supply and demand to get the most optimal results.

This study uses the HOMER software. This software can design systems and simulate systems and determine the best system configuration [8]. In previous studies, there has been no specific discussion regarding the optimal design method for renewable applications in 
disaster areas. It also discusses the application of renewable energy for disasters that is still static or not mobile and functionally separate or not as a single system.

\section{MATERIAL}

A hybrid system is a power generation system that consists of two or more power generation technologies. For example, solar electricity (Photovoltaic-PV) combined with a generator is called a Hybrid PV-Genset. In Indonesia, there have been many applications of Hybrid PVGenset, Hybrid PV-Microhydro, PV-Wind (Wind), and even Hybrid-Wind-Genset [9][10].

The hybrid system design is base on load power capacity, daily load profile, and solar intensity. From these data, the percentage contribution of renewable energy sources, such as solar energy, is determined through the conversion of solar modules and diesel engines.

In this study, the hybrid model system used is combining PV and wind turbines as an energy source. PV and wind turbines work alternately according to weather conditions. The main objective of the hybrid system is to maximize energy at a low price, pollution-free, good power quality, and sustainable energy.

\subsection{PV Panel}

Current photovoltaic depends on irradiance and temperature of the cell:

$I_{p v}=\left[I_{s c}+K_{i}\left(T-T_{\text {ref }}\right)\right] x \frac{G}{1000}$

Here: $\mathrm{G} \quad=$ Irradiance $\left(W / \mathrm{m}^{2}\right)$

Isc $=$ Short circuit current under standard test conditions

$\mathrm{Ki}=$ Coefficient with temperature

Tref $=298 \mathrm{~K}$

PV panel Output given by voltage battery:

$V_{d c}=V_{p v} \times N_{c}$

Here: $\quad \mathrm{Vdc} \quad=$ Voltage on DC bus

$\mathrm{Vpv} \quad=$ Nominal voltage of PV panel

$\mathrm{Nc} \quad=$ Number of cell

Output power PV:

$P_{p v}=I_{s c} x G \times V_{p v} \times \frac{N_{c}}{K_{f}}$

Here: $K_{f} \quad=$ Loss factor

\subsection{Wind Turbines}

The calculation of the power that can be generated by a wind turbine is as follows:
$P_{w d}=\frac{1}{2} \times A \times \rho a \times v^{3}$

Here: $P_{w d}=$ Output power wind turbines (watt)

$$
\begin{array}{ll}
\rho & =\text { Wind coefficient }\left(1,225 \mathrm{~kg} / \mathrm{m}^{3}\right) \\
A & =\text { Cross section }\left(\mathrm{m}^{2}\right) \\
V & =\text { Wind speed }(\mathrm{m} / \mathrm{s})
\end{array}
$$

\subsection{Battery system}

Storage capacity of the battery is:

$$
S=\frac{\left(E \times N_{\text {day }}\right)}{\left({ }^{\mathrm{p}}{ }^{\mathrm{\eta}}{ }^{\mathrm{\eta}}{ }_{b} \times D O D\right)}
$$

$$
\begin{array}{ll}
\text { Here: } & \text { S } \\
\text { E } & =\text { Storage capacity } \\
N_{d a y} & =\text { Number of days without charging } \\
{ }_{{ }_{c}} & =\text { Convertor yield } \\
{ }_{b} & =\text { Battery yield } \\
\text { DOD } & =\text { Depth of discharge }
\end{array}
$$

\section{METHOD}

In this study, there are a series of stages that must be pass to achieve the expected research objectives. The first is to collect data related to solar radiation and wind speed data obtained from NASA and then identify and profile the electrical load. The second is planning a PV hybrid system - wind turbines using the HOMER software. The third is to simulate and optimize with variations of the four configurations and evaluate. The results from the evaluation with the best optimization will be used as the final result. The fourth one is applying hardware design and applying it in real word.

\subsection{Block Diagram System}

The hybrid system PV-wind turbines shown in Figure 1 , the output power will be store before being transferred to the load because the power generated by the hybrid system (PV-wind turbine) is not fixed depending on the wind speed factor and solar radiation. PV-wind turbines get excess wind speed or solar radiation then will be stored in the battery.

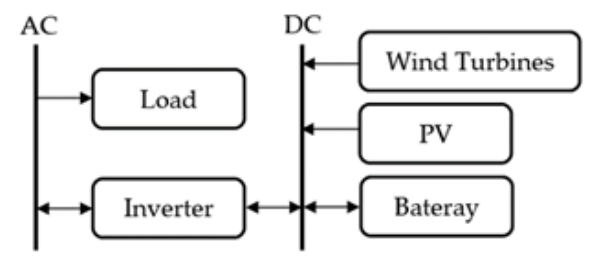

Figure 1 Block diagram of hybrid system

Figure 1 shows where all generators PV and wind turbines are connected to the electrical interface in DC- 
bus, then enter the inverter system with a battery and connected to the main AC-bus before being supplied to the load (grid). Architecture is referred to as AC centralized architecture because the power generated by all generators is connected to the load through a single point. Since the output of hybrid system and battery is $\mathrm{DC}$ voltage, an inverter is needed to convert DC to AC voltage.

\subsection{Photovoltaic $(P V)$}

The photovoltaic used in the schematic design of the hybrid system using the Monocrystalline PV type with four PV configurations are 250wp, 270wp, 300wp, and 310wp. To set photovoltaic in HOMER software shown in Figure 2.

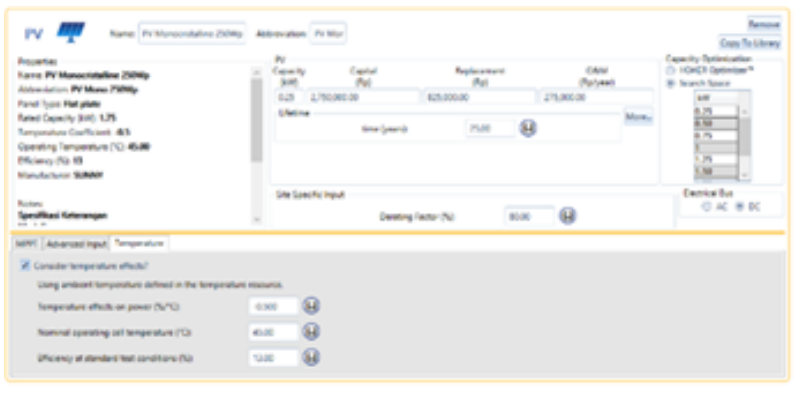

Figure 2 Photovoltaic setting

\subsection{Battery}

The battery used in the schematic design of the hybrid system uses a GED Series-Deep Cycle 12V 100Ah type battery and can use for five years. battery settings in the HOMER software shown in Figure 3.

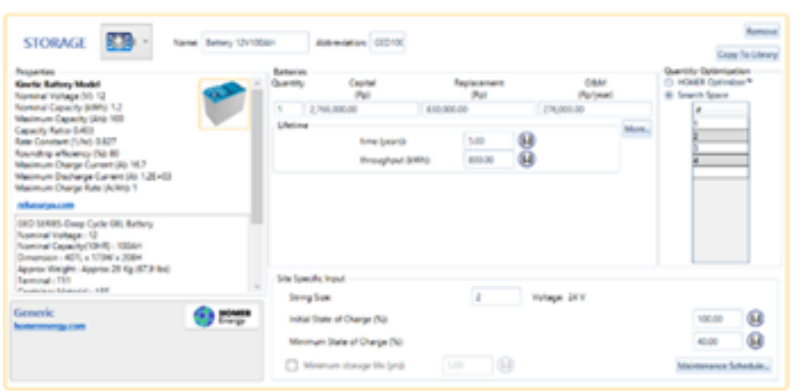

Figure 3 Battery setting

\subsection{Converter}

The converter used in designing the hybrid system schematic uses the TEP 1500W type, Input Voltage 12V $24 \mathrm{~V} 48 \mathrm{~V}$, output voltage $110 \mathrm{~V} / 220 \mathrm{~V}$. The inverter as much as one piece with a capacity of $1.5 \mathrm{~kW}$ and can be used for 15 years. In the HOMER software, the window used to adjust the converter shown in Figure 4.

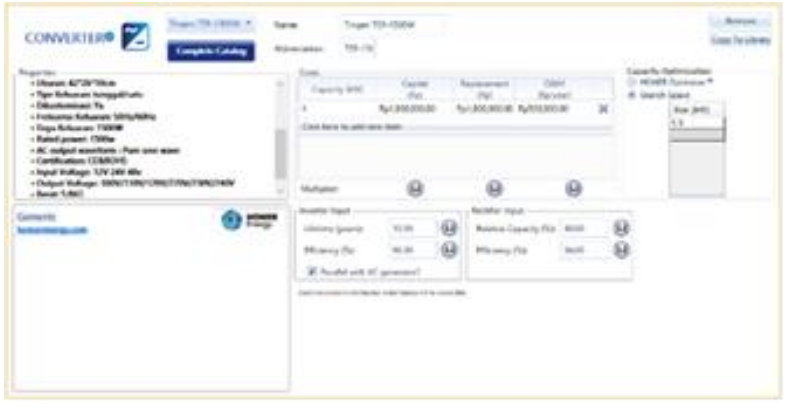

Figure 4 Converter setting

\subsection{Wind Turbines}

The wind turbine used to design the hybrid system uses one type of Wind V GV-1kW with a capacity of 1 $\mathrm{kW}$ and can use for 20 years Figure 5 shows the wind turbine setup window in the HOMER software.

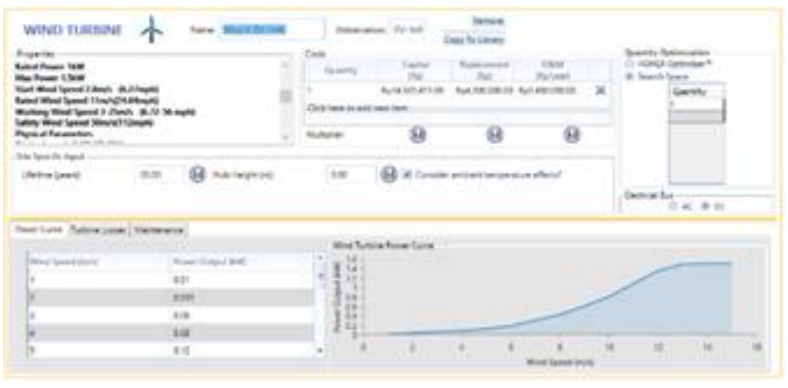

Figure 5 Wind turbines setting

\subsection{Wind Speed}

The wind speed in the Cepu area is obtained from NASA, Figure 6 shows the wind speed data per month in the HOMER software. In the HOMER software, wind speed data for a year needed to be able to simulate a wind turbine.

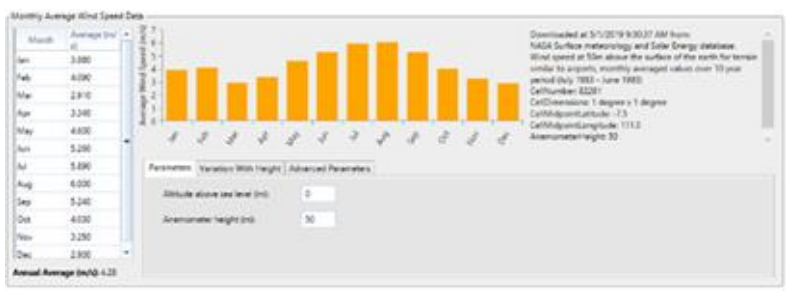

Figure 6 Wind turbines setting

The average wind speed obtained from the study location varies between $4-7 \mathrm{~m} / \mathrm{s}$ per month. With the value of wind speed generated in the research location that can use to rotate wind turbines, the minimum wind speed value is $4.28 \mathrm{~m} / \mathrm{s}$.

\subsection{Solar Radiation}

Solar radiation data in the Cepu area obtained through NASA with the help of HOMER will connect to NASA satellites via the internet by providing the location of the 
latitude and longitude of the research location. Solar radiation data in the HOMER simulation software requires a year of data to be able to make a photovoltaic. From the NASA, data on solar radiation per month obtained shown in Figure 7.

\subsection{Load}

This daily needs data taken from the load identification data that will be used in the emergency event as shown in Table 1.

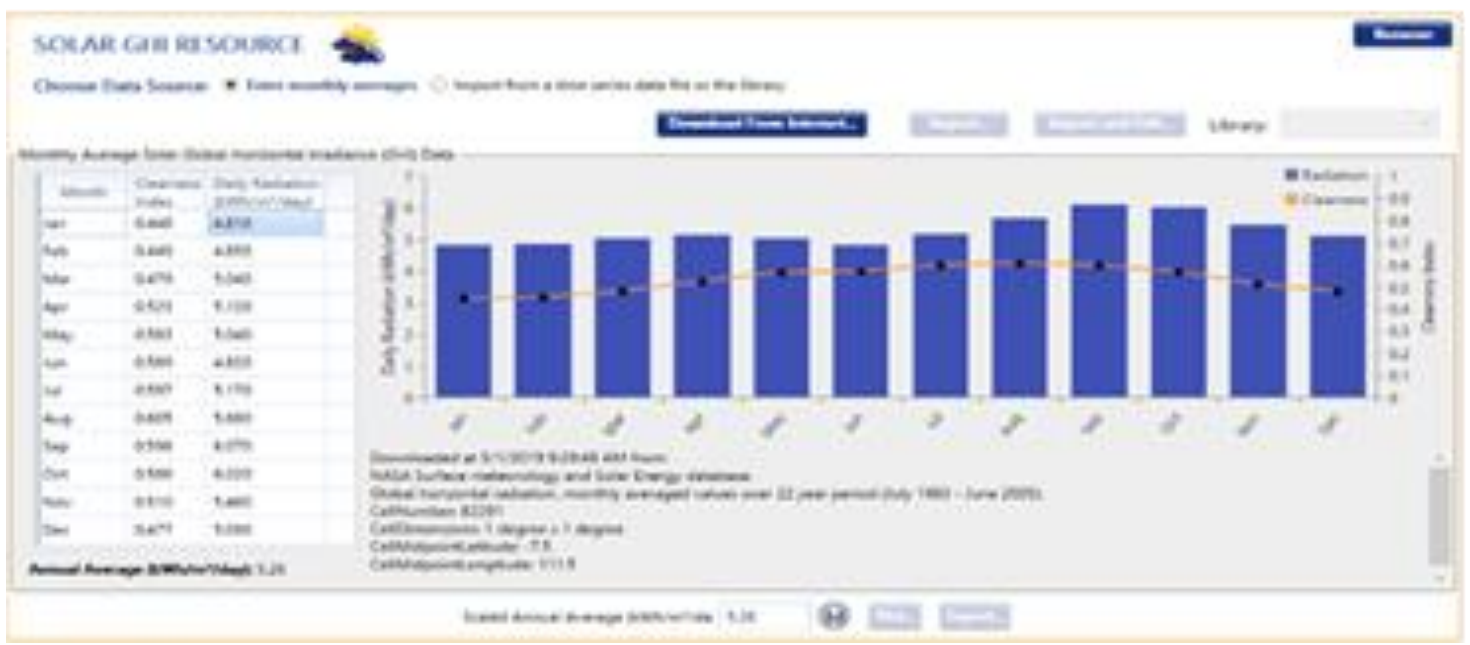

Figure 7 Wind turbines setting

Table 1. Load data

\begin{tabular}{llccc}
\hline No & Load & Power (Watt) & Period Time (hours) & Energy (Wh) \\
\hline 1 & Water pump & 750 & $07.00-14.00$ & 7500 \\
2 & Reverse osmoses & 96 & 24 & 2304 \\
3 & Lamp (6 x 6 watt) & 36 & $(00.00-06.00)(18.00-24.00)$ & 468 \\
4 & Socket and Charger & 37.5 & 24 & 900 \\
Estimated Total Usage Load per day & & & 9672 \\
\hline
\end{tabular}

After the load is input, then proceed with adjusting the usage of the load per hour in a day. Before regulating the use of the load per hour in a day, first, add up the overall data on the total electricity consumption of the community per month to get the average load per month in a year. In regulating the use of hourly loads in a day, the data entered is data on the average load per month in a year used by the community. The column side of the day load setting shows the hourly load usage time, while the row side shows the names of the months that will be set the load. Load per hour of day shown in Figure 8.

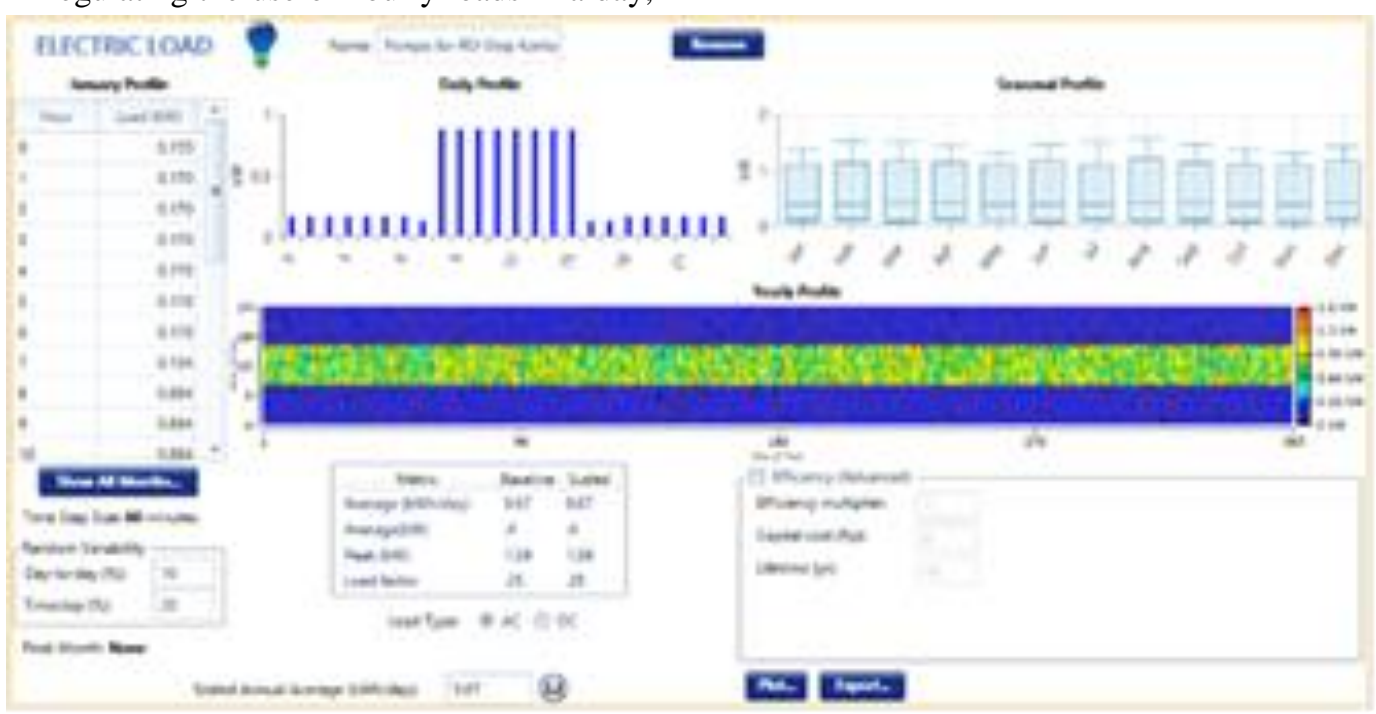

Figure 8 Daily curve profile 


\section{SIMULATION RESULT AND ANALYSIS}

The simulation is done using HOMER software on a hybrid system (PV-Wind turbines) shown in Figure 9. Hybrid planning (Wind - PV) using a load of $9.67 \mathrm{~kW} \mathrm{/}$ day. Electricity supply from two sources, namely

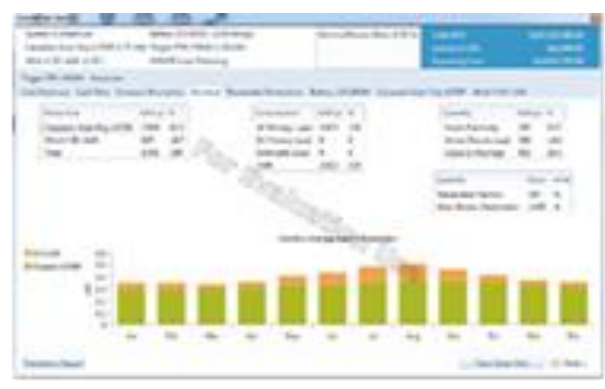

(a)

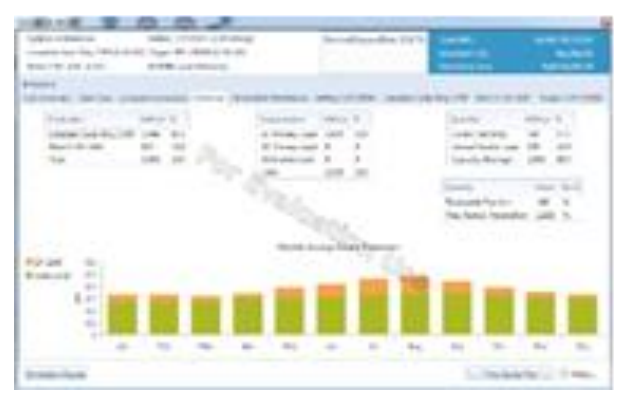

(b)

Figure 9 HOMER simulation result

Figure 9(a) shows the electricity production, namely electricity production from PV of $2899 \mathrm{kWh} / \mathrm{yr}$ with a fraction of $81.3 \%$, electricity production from wind turbines of $663 \mathrm{kWh} / \mathrm{yr}$ with a fraction of $18.7 \%$. The total electricity production generated is $3566 \mathrm{kWh} / \mathrm{yr}$. Meanwhile, the power consumption from the AC primary load is $3023 \mathrm{kWh} / \mathrm{yr}$. The annual electricity production generates more than the power consumption that an excess of $543 \mathrm{kWh} / \mathrm{yr}$ of electricity. In first configuration, it can see there is optimal electricity production in June September. The maximum electricity production is in August, while the lowest electricity production occurs in March, November, December. Figure (b) the electricity production produced is electricity from $\mathrm{PV}$ of $2698 \mathrm{kWh} / \mathrm{yr}$ with a fraction of $80.2 \%$, electricity production from wind turbines of $667 \mathrm{kWh} / \mathrm{yr}$ with a fraction of $19.8 \%$. The total electricity production generated is $3365 \mathrm{kWh} / \mathrm{yr}$. Meanwhile, the power consumption that comes from the AC primary load is $2935 \mathrm{kWh} / \mathrm{yr}$. The annual electricity produced is more than the power consumption, so an excess of $430 \mathrm{kWh} / \mathrm{yr}$ of electricity. In configuration two, the optimal electricity production in June - September. The maximum electricity production is in August, while the lowest electricity production occurs in March, November, December. Figure (c) The electricity production photovoltaic and wind turbines. The first source is the Wind V GV-1kW wind turbine with a nominal power of $1 \mathrm{KW}$. The second source is PV with four configurations. Distributed the power output from the wind turbine to the battery converter with a capacity of $1.5 \mathrm{~kW}$ is used, while the battery type GED100-12 with a nominal voltage of 12 V.

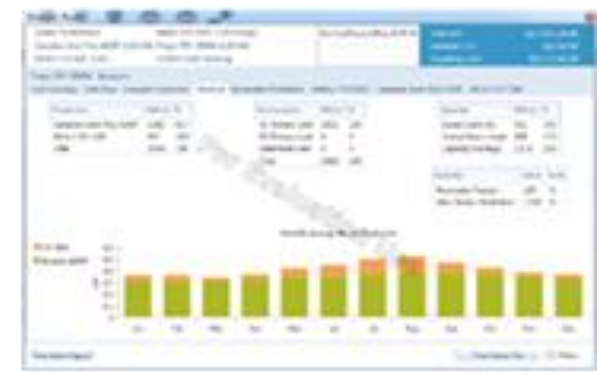

(c)

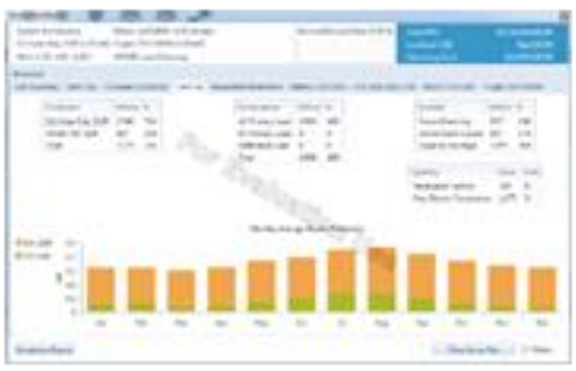

(d)

produced is electricity from $\mathrm{PV}$ of $2982 \mathrm{kWh} / \mathrm{yr}$ with a fraction of $81.7 \%$, electricity production from wind turbines of $667 \mathrm{kWh} / \mathrm{yr}$ with a fraction of $18.3 \%$. The total electricity production generated is $3649 \mathrm{kWh} / \mathrm{yr}$. The power consumption that comes from the AC primary load is $2922 \mathrm{kWh} / \mathrm{yr}$. The annual electricity production generates more than the power consumption that an excess of $727 \mathrm{kWh} / \mathrm{yr}$ of electricity. The third configuration shows that there is optimal electricity production in June - September. The maximum electricity production is in August, the lowest electricity production occurs in March, November, December. Figure (d) The electricity production generated from PV is $2568 \mathrm{kWh} / \mathrm{yr}$ with a fraction of $79.4 \%$, electricity production from wind turbines is $667 \mathrm{kWh} / \mathrm{yr}$ with a fraction of $20.6 \%$. The total electricity production generated is $3235 \mathrm{kWh} / \mathrm{yr}$. Meanwhile, the power consumption from the AC primary load is $2904 \mathrm{kWh} / \mathrm{yr}$. The annual electricity production generates more than the consumption that an excess of $331 \mathrm{kWh} / \mathrm{yr}$ of electricity. The fourth configuration shows that there is optimal electricity production in June - September. The maximum electricity production is in August, while the lowest electricity production occurs in March, November, December. 


\section{HARDWARE}

Figure 10 shows a hardware design using threedimensional software. The design is realized in the form of real hardware.

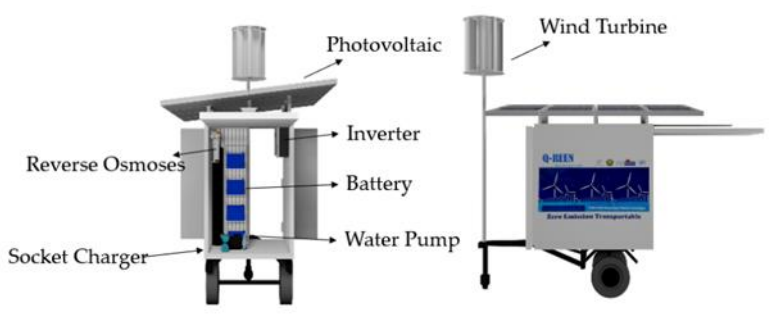

Figure 10 Hardware

\section{CONCLUSION}

In this study, the Design of PV-Wind Turbine Mobile Container for Disaster Area Using Homer can obtain the most optimal configuration results. The most optimal configuration in the first configuration after comparing the four tested. The first configuration has the second largest electricity production and first power consumption, the least excess electricity, unmet electric load, and capacity shortage, and easy to assemble because it has dimensions smaller than others even though it is the second-lowest-cost factor of the configuration with other.

\section{REFERENCES}

[1] Sobel, R.S. and P.T. Leeson, The use of knowledge in natural-disaster relief management. The Independent Review, 2007. 11(4): p. 519-532.

[2] Vosen, S. and J. Keller, Hybrid energy storage systems for stand-alone electric power systems: optimization of system performance and cost through control strategies. International journal of hydrogen energy, 1999. 24(12): p. 1139-1156.
[3] Bidisha Roy, Ashoke Kumar Basu, Subrata Paul, "Optimal design of a grid connected solar photovoltaic power system for a residential load.,"

[4] Majid Alabdul Salam, Ahmed Aziz, Ali H A Alwaeli, Hussein A Kazem, "Optimal sizing of photovoltaic systems using HOMER for Sohar,Oman"

[5] Mason, J. E., and Archer, C. L. (2012). "Baseload electricity from wind via compressed air energy storage (CAES)." Renewable Sustainable Energy Rev., 16(2), 1099-1109.

[6] A. Musse. M., and S. Marizan, "Design and Proper Sizing of Solar Energy Schemes for Electricity Production in Malaysia,"National Power and Energy Conference (PECon) Proceedings, pp.268 271, 2003.

[7] F. Giraud, and Z. M. Salameh, "Steady-state performance of a grid connected rooftop hybrid wind-photovoltaic power system with battery storage," IEEE Trans. on Energy Conversion, vol. 16, no.1, pp. 1-7, 2001.

[8] ] Nejad S, Iqbal T, Quaicoe J. A compressed air energy storage system: design and steady state performance analyses,

[9] Ibrahim, H.; Younès, R.; Basbous, T.; Ilinca, A.; Dimitrova, M. Optimization of diesel engine performances for a hybrid wind-diesel system with compressed air energy storage. Energy 2011, 36, 3079-3091.

[10] Lund, H.; Østergaard, P. A.; Connolly, D.; Ridjan, I.; Mathiesen, B. V.; Hvelplund, F.; et al. Energy storage and smart energy systems. Int. J. Sustain. Energy Plan. Manag. 2016, 11, 3-14. 